Revista de la red interuniversitaria de estudios sobre las literaturas rioplatenses contemporáneas en Francia

$18 \mid 2018$

El río y la ciudad

\title{
Apostillas para el miope
}

\section{Hernán Hevia}

URL: http://journals.openedition.org/lirico/5735

DOI: 10.4000/lirico.5735

ISSN: 2262-8339

Editor

Réseau interuniversitaire d'étude des littératures contemporaines du Río de la Plata

Referencia electrónica

Hernán Hevia, « Apostillas para el miope », Cuadernos LIRICO [En línea], 18 | 2018, Puesto en línea el 14 octubre 2018, consultado el 21 abril 2019. URL : http://journals.openedition.org/lirico/5735 ; DOI 10.4000/lirico.5735

Este documento fue generado automáticamente el 21 abril 2019.

\section{(c) (i) $(9$}

Cuadernos LIRICO está distribuido bajo una Licencia Creative Commons Atribución-NoComercialSinDerivar 4.0 Internacional. 


\title{
Apostillas para el miope
}

\author{
Hernán Hevia
}

\section{Memoria descriptiva}

Dos epígrafes acompañan la gentil invitación a participar del dossier "El río y la ciudad": uno, de El entenado, funda, del río a la orilla, una estirpe; el otro, de El río sin orillas, confirma, después de otear el horizonte, que acaso ya no haya más nada.

En "A medio borrar", un puente colgante es amenazado por una inundación; el espacio delimitado resulta, a pesar de su creciente expansión, más puntual: anfibio. "Cuando estamos inclinados entre los escombros mirando el torrente que atraviesa - ¿en qué dirección?- la brecha, donde las planicies se juntan casi sin ruido...". La levedad proyecta una experiencia por deslizamientos.

Del mismo modo, aunque en otra escala, el cuadro que está pintando Héctor, de quien también se terminará despidiendo el narrador, es tan blanco como la pared sobre la que apenas se recorta, se suspende -está en un caballete-; pero su cualidad horizontal resulta menguada por lo ancho del taller. El cuadro “...tengo la impresión, como quien dice, se borra. Es una blancura exclusivamente vertical". Releyendo La mayor se esboza un efecto asociado a una idea de figuración.

Al mismo tiempo, trazar un cauce, otra inflexión, supondría no prescindir de una fórmula de Walsh de la misma época: el Río de la Plata fue, y así permanece, alfombrado de muertos.

¿Qué habría sucedido si, en 1999, Charly García, en lugar de anunciarlo tantas veces, hubiera arrojado maniquíes al río mientras tocaba Los dinosaurios? Unos años después, el Proyecto Filoctetes: Lemnos en Buenos Aires los caracterizó para diseminarlos por la Capital Federal (o, más bien, por su mitad hacia el Este, la mitad hacia la costa). Los arrojados desde el aire hubieran permanecido flotando en el río; los de la intervención diseñada por E. García Wehbi fueron recolectados el mismo día a la tarde temprano. Las reacciones, para obliterarlas o como corolario estadístico (¿un maniquí en el Oeste no se hubiera cruzado con nadie y seguiría hasta hoy allí?), resultaban un fin. El horizonte participativo que El siluetazo, su verosímil antecedente, le había agregado a una tradición de posguerra 
cedía, más que al distanciamiento, a la provocación. Como sea, estas obras no perturbarían la prescindencia de las mansas aguas.

¿Y si Edgardo Antonio Vigo, en 1973, el año de su “acción”, hubiera tirado del tapón del Río de la Plata? ¿Y si se hubiera revertido la dirección del flujo de agua?

Otra promesa conforma una referencia más específica de ¿una escena?: para el plan de viviendas en el Bajo Belgrano, Kurchan y Ferrari Hardoy encargaron una propaganda. "La ciudad frente al río. Tercera fundación" es, mutatis mutandis, un remedo de La ciudad, el cortometraje de 1939 de Van Dyke y Steiner con textos de Lewis Mumford incluido en la exhibición "La ciudad del futuro": apela al acervo de tipicidades históricas del lenguaje del cine, en especial del género "película para arquitectos", para condicionar reacciones. Si para proponer un hábitat más armonioso y en comunión con la naturaleza hay que demostrar lo caótico de la ciudad y las consecuencias de la congestión, es obvio que se deben citar genéricamente, sin densidad, los ya reconocibles montajes entrecortados y angulaciones exorbitantes de las vanguardias de principios del siglo veinte -antes de que las crisis convirtieran a las grandes urbes en demonios- y oponerlos a la mirada abarcadora de una maqueta; la carencia de organización seguía mirando al lado abierto, nuevamente el Este. Y quizás por eso, los cortos que debieron completar la serie (a excepción de uno dedicado al tránsito, circunscripto a zonas fronterizas entre la Capital y el Conurbano) quedaron inconclusos. Se sabe: la perspectiva escenográfica, desde esta u otra orilla, apacigua, determina la posición de un espectador.

Lo paisajístico estalló con un contrapunto de bandas sonoras (declamaciones, citas a Eliot y Lautréamont, la batería desquiciada de Week-end...) en El río, de Rafael Filippelli.

Algunos años atrás se recuperaron expedientes con fotos de los cadáveres que el río devolvió a las orillas. La visibilidad del río no podría resultar ajena a esta ansiada novedad; Welles afirmaba que no debía dejarse pasar la oportunidad de incluir, cuantas veces fuera posible, lo filmado durante la apertura de los campos.

Como un basamento, la serie de fotos podría sobrepasar el límite del bloque en el que se muestra el río e ir puntuando la película en su totalidad. Al mismo tiempo, a lo sumo dos de las fotos podrían ser incluidas en el bloque. Además, se podría agregar una pantalla en negro de la misma duración. O mejor: un plano filmado (ver el guión técnico) en cine y de noche. ¿Quién iluminaría el río?

Después de dos epifanías: la visibilidad difuminada por el halo del fuego de un vela mientras suena un piano en un baile en Usher Island y una cámara se detiene en un perro cómplice en la base del Toro Farnese en una pinacoteca, antiguo cuartel de caballería, en Nápoles.

El río con una misma orilla. A lo sumo, un exordio didáctico; ver en la homogeneidad: hiatos que estrían la superficie e inserts que se propagan.

Para ver el fondo, ¿cómo quedar al ras?

22 de mayo de 2018

\section{Guión técnico}

(para una película cualquiera)

Filmar cuatro pares de planos del río en el mismo horario pero en diferentes días.

Elegir dos puntos de la costanera norte, no muy lejos de Aeroparque, el club de pescadores y el trasplantado monumento a Cristóbal Colón, desde donde, además, se pueda ver: 1) casi a los pies, arrimándose a la baranda, la escollera en declive y el río. 2) El río cercado por la escollera. 
Ubicar la cámara entre dos alturas tope, de modo que el punto medio entre ambas sea el de los ojos del camarógrafo. El movimiento de ida y vuelta recorre una línea imaginaria a cuarenta y cinco grados del camarógrafo.

Llegando al tope más alto, alcanzar una posición casi cenital. Del mismo modo, al retraer la cámara en diagonal hacia abajo, compensarlo con un paneo hacia arriba (travelling con panorámica invertida), pero sin sobrepasar la línea del horizonte.

Cambiar el lente.

Las duraciones de los planos deben ser similares. (Advertencia: la velocidad de la panorámica que va de la lejanía hacia lo cercano sería menor a su correspondiente.)

Durante la filmación de los planos, liberar el movimiento y acompasarse momentáneamente a algunas estelas o pequeñas olas (para luego, en el montaje, eventualmente, empalmarlas en continuidad), y seguir.

Cada plano va acompañado de su respectivo sonido directo: comentarios prosaicos, música de carritos, viento, aviones, tránsito de fondo, el golpe del agua con las piedras, alguien que llama a otro para mostrarle lo que pescó, etc.

Al menos un corte tiene que ser entre los momentos en que, obviamente, entre dos planos diferentes, solo se ve el río. En lo posible, que el corte en continuidad sea entre aquellos planos que repasan la misma zona del río.

(A manera de pruebas: algunas fotos de la línea de tiempo con diversas variantes de montaje; también, un fragmento de "La mayor".)

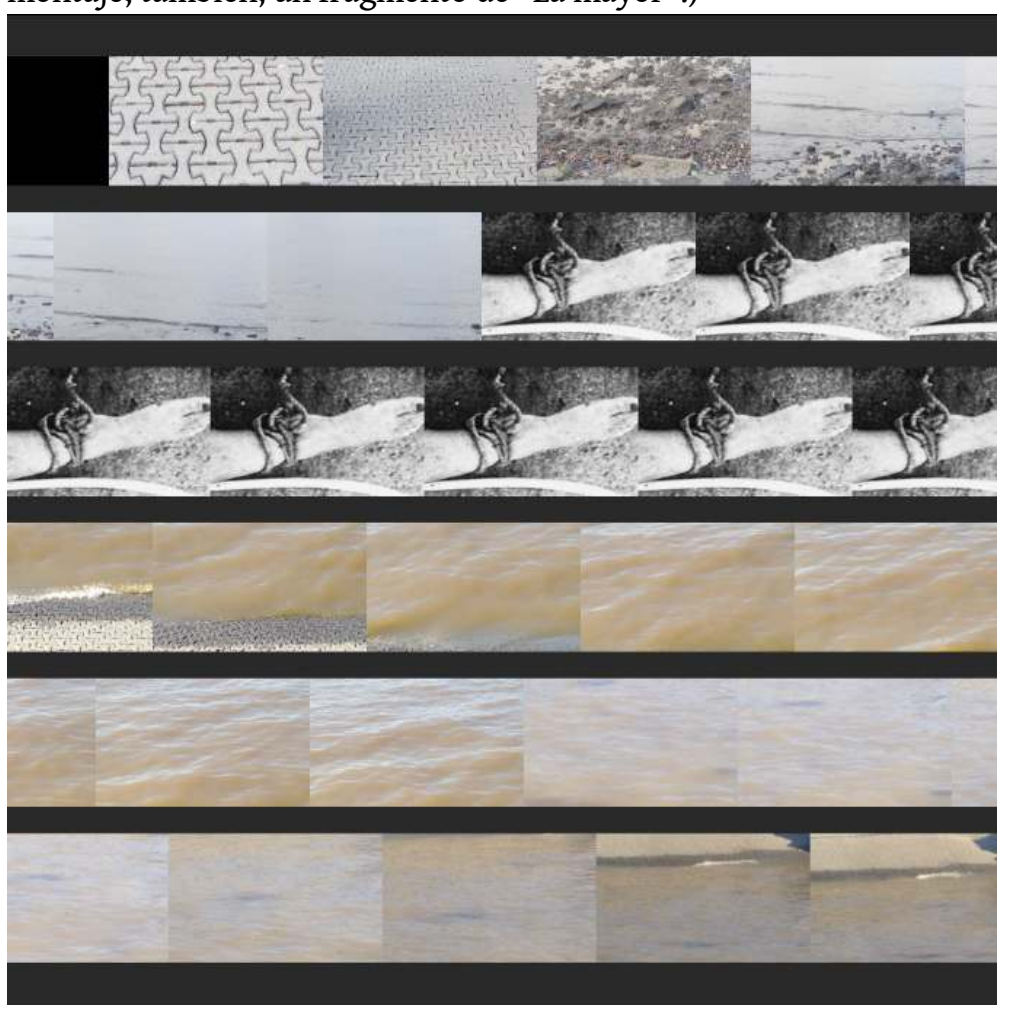

1. MONTAJE. VARIACIÓN 4 


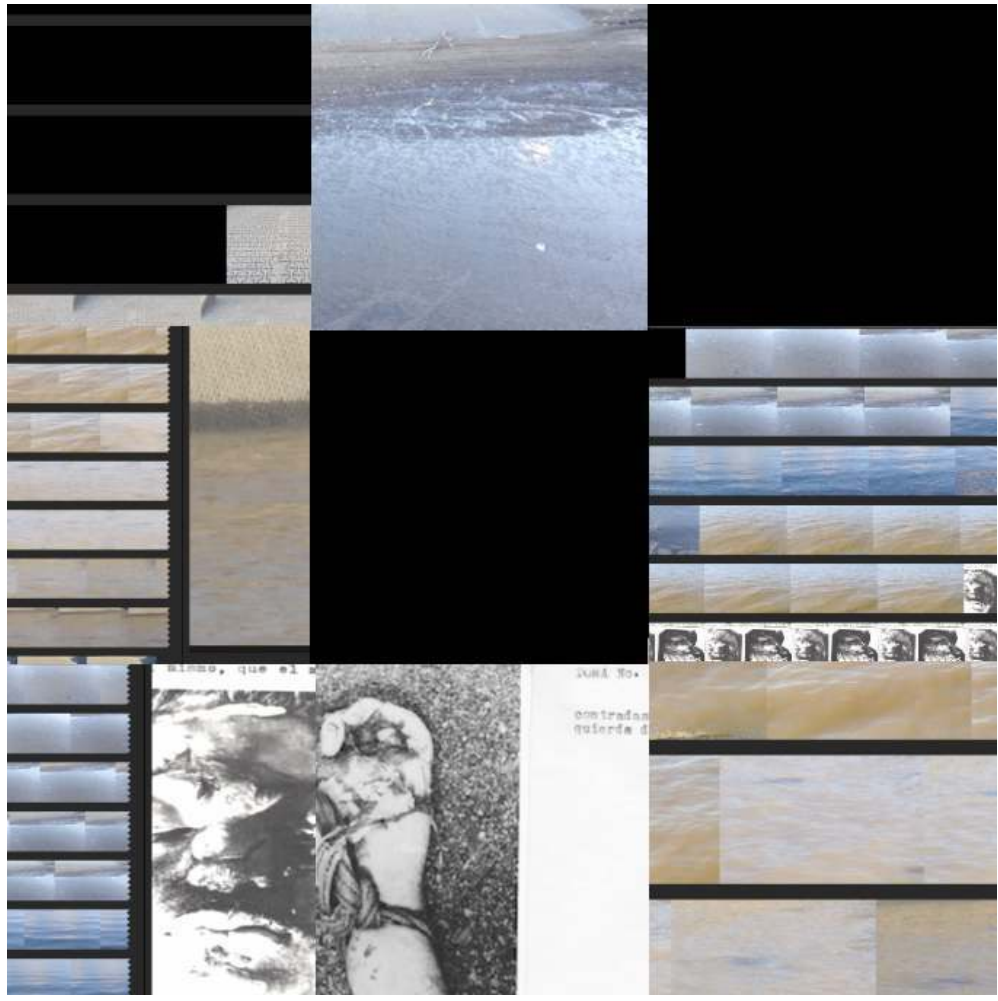

2. MONTAJE. VARIACIÓN 11, VARIOS ESTADOS (DESORDENADOS)

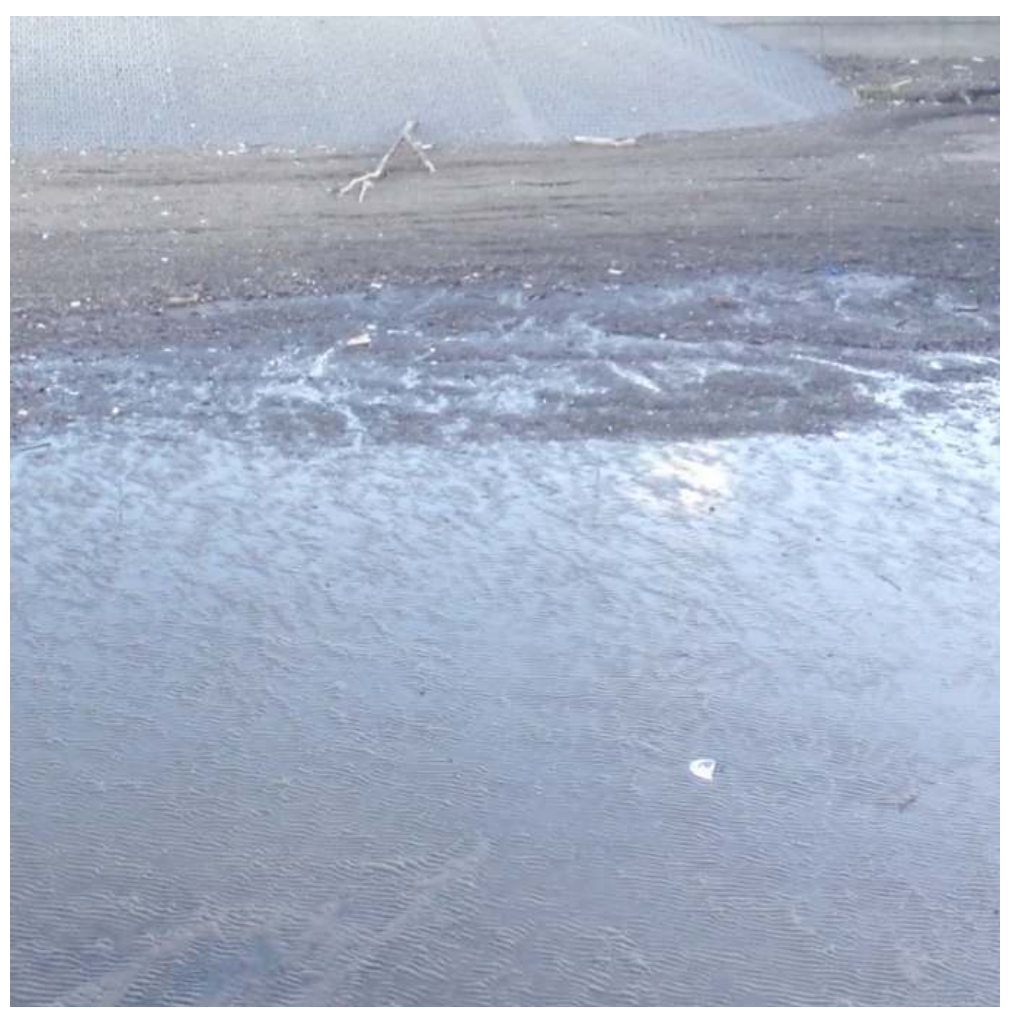

3. UN PLANO 
blanco que parece ceniza volcánica. Ahora no vemos más nada. Sentimos que el otro cuerpo está caliente, espeso, socarrado. Imaginamos que el nuestro ha de estar así, también. Nos trenzamos en una lucha intermitente, alternada con momentos de completa inmovilidad, en los que vemos nuestra pelambre, nuestras rodillas, nuestros genitales que se corresponden, que se complementan, los pies plácidos, nudosos, separados en el extremo de la cama; comparamos las partes quemadas de nuestro cuerpo con las partes blancas, en el lugar en que acostumbramos llevar el traje de baño. Después nos trenzamos en la lucha final. Habíamos tocado el punto extremo, el fondo barroso del río, pasado el lecho y llegado a una zona translúcida más allá del fondo convulsionado y enceguecedor, un punto lleno de luz como el centro mismo de un diamante. Esa luz era tan intensa que no dejaba ver nada, ni la misma luz. En la lucha subimos otra vez, sa que no de anogado, hacia la oscuricompactos y en remolino, como el cuerpo de un. Ḿ́s arriba está todavia la dad confusa del fondo en la que nos debatimos. Más arriba está codavía la superficie del mundo con el balneario, los caminos, la muchedumbre, la ciudad, la cámara oscura en la que nuestros cuerpos, ahora, están tirados ciudad, la cán la cama, mirando el cielorraso. A mediodía nos habíamos inmóviles sobre la cama, mo de escuchar el rumor múltiple del agua, poliparado en la orilla tratando de escuchar el rumor mín rrítmico y polifónico en el corazón de su lenta monotonía. No distinguimos nada en ese rumor, salvo que era un rumor que sonaba inquietándomos nada nos un poco y que na raya, grumo de nervios y cartílagos, tendida a otro lado de la barrera, una raya, grumo de calor del agua menos profunda, cree de golpe percibir - en la gran confusión de sus sentidos subacuáticos- un rumor vago y monótono que manda el balneario, un rumor del que no sabe que está compuesto de muchas voces y es el canto del mundo.

\section{El bar de Gandia}

\section{4. ¿UN OVER?}

